\title{
Effects of parathyroid hormone rhPTH(1-84) on phosphate homeostasis and vitamin $D$ metabolism in hypoparathyroidism: REPLACE phase 3 study
}

\author{
Bart L. Clarke ${ }^{1}{ }^{1} \cdot$ Tamara J. Vokes $^{2} \cdot$ John P. Bilezikian $^{3} \cdot$ Dolores M. Shoback $^{4}$ • \\ Hjalmar Lagast ${ }^{5} \cdot$ Michael Mannstadt $^{6}$
}

Received: 27 April 2016 / Accepted: 30 September 2016 / Published online: 12 October 2016

(C) The Author(s) 2016; This article is published with open access at Springerlink.com

\begin{abstract}
In hypoparathyroidism, inappropriately low levels of parathyroid hormone lead to unbalanced mineral homeostasis. The objective of this study was to determine the effect of recombinant human parathyroid hormone, rhPTH (1-84), on phosphate and vitamin D metabolite levels in patients with hypoparathyroidism. Following pretreatment optimization of calcium and vitamin D doses, 124 patients in a phase III, 24-week, randomized, double-blind, placebo-controlled study of adults with hypoparathyroidism received subcutaneous injections of placebo or rhPTH(1-84)
\end{abstract}

Electronic supplementary material The online version of this article (doi:10.1007/s12020-016-1141-0) contains supplementary material, which is available to authorized users.

Hjalmar Lagast, Amicus Therapeutics, Inc. 1 Cedar Brook Drive, Cranbury, NJ 08512, USA

Bart L. Clarke

clarke.bart@mayo.edu

1 Division of Endocrinology, Diabetes, Metabolism, and Nutrition, Mayo Clinic, E18-A, 200 1st Street SW, Rochester, MN 55905, USA

2 Section of Endocrinology, University of Chicago Medicine, 5841 South Maryland Avenue, MC1027, Chicago, IL 60637, USA

3 Division of Endocrinology, College of Physicians and Surgeons, Columbia University, 630 W 168th Street, Room 864, New York, NY 10032, USA

4 Endocrine Research Unit, San Francisco Department of Veterans Affairs Medical Center, University of California, 1700 Owens Street, San Francisco, CA 94158, USA

5 NPS Pharmaceuticals, Inc., 300 Shire Way, Lexington, MA 02421, USA

6 Endocrine Unit, Massachusetts General Hospital and Harvard Medical School, 50 Blossom Street, Thier-1123, Boston, MA 02114, USA
(50 $\mu \mathrm{g} / \mathrm{day}$, titrated to 75 and then $100 \mu \mathrm{g} / \mathrm{day}$, to permit reductions in oral calcium and active vitamin $\mathrm{D}$ doses while maintaining serum calcium within $2.0-2.2 \mathrm{mmol} / \mathrm{L}$ ). Predefined endpoints related to phosphate homeostasis and vitamin D metabolism were analyzed. Serum phosphate levels decreased rapidly from the upper normal range and remained lower with $\mathrm{rhPTH}(1-84)(P<0.001$ vs. placebo $)$. At week 24, serum calcium-phosphate product was lower with $\operatorname{rhPTH}(1-84)$ vs. placebo $(P<0.001)$. $\operatorname{rhPTH}(1-84)$ treatment resulted in significant reductions in oral calcium dose compared with placebo $(P<0.001)$ while maintaining serum calcium. After pretreatment optimization, baseline serum 25-hydroxyvitamin D (25[OH]D) and 1,25-dihydroxyvitamin $\mathrm{D}\left(1,25[\mathrm{OH}]_{2} \mathrm{D}\right)$ levels were within the normal range in both groups. After 24 weeks, $1,25(\mathrm{OH})_{2} \mathrm{D}$ levels were unchanged in both treatment groups, despite significantly greater reductions in active vitamin D dose in the $\operatorname{rhPTH}(1-84)$ group. In hypoparathyroidism, rhPTH (1-84) reduces serum phosphate levels, improves calcium-phosphate product, and maintains $1,25(\mathrm{OH})_{2} \mathrm{D}$ and serum calcium in the normal range while allowing significant reductions in active vitamin $\mathrm{D}$ and oral calcium doses.

Keywords Hypoparathyroidism · Phosphate $\cdot \operatorname{rhPTH}(1-84) \cdot$ Parathyroid hormone $\cdot$ Vitamin D

\section{Introduction}

Hypoparathyroidism is a rare disorder of unbalanced mineral homeostasis resulting from absent or inappropriately low levels of endogenous parathyroid hormone (PTH) 
[1-3]. Although hypocalcemia is a classic hallmark of hypoparathyroidism, hyperphosphatemia, and hypomagnesemia may also occur [4]. PTH acts directly on bone, increasing turnover, and resulting in the release of calcium and phosphate into the circulation $[4,5]$. In the kidney, PTH stimulates renal reabsorption of calcium, promotes phosphate excretion in the urine, and enhances the conversion of 25-hydroxyvitamin $\mathrm{D}(25[\mathrm{OH}] \mathrm{D})$ to the active 1,25-dihydroxyvitamin $\mathrm{D}\left(1,25[\mathrm{OH}]_{2} \mathrm{D}\right)$ metabolite, which increases transepithelial transport of dietary calcium and phosphate from the intestine [4-6]. In concert, these effects help maintain normal serum calcium and phosphate levels.

With standard conventional management, the goal is to maintain serum calcium at the low end of the normal range while attempting to avoid both hypocalcemia and hypercalciuria as well as hyperphosphatemia, which can increase the calcium-phosphate product [4, 5]. Despite the clinical feasibility of therapy with oral calcium and active vitamin D (calcitriol or alfacalcidol), albeit used often in large amounts, important complications can ensue. Conventional therapy can lead to hypercalciuria, which in turn can result in nephrolithiasis and nephrocalcinosis, and irreversible kidney damage $[4,5,7]$. Active vitamin D metabolites do not replace the phosphaturic action of PTH and might exacerbate hyperphosphatemia by enhancing intestinal phosphate absorption [4]. Elevated serum phosphate levels may increase the serum calcium-phosphate product, thereby raising the risk for precipitation of calcium-phosphate. In patients with advanced renal disease, elevated serum phosphate levels and higher serum calcium-phosphate product were associated with coronary calcifications and increased mortality risk [8, 9]. In patients with hypoparathyroidism, calcification complexes have been reported in soft tissues, particularly the brain, lens, and kidney, but also the vasculature and other tissues [5, 7, 10-12]. Recent guidelines recommend maintaining calcium-phosphate product levels below $4.4 \mathrm{mmol}^{2} / \mathrm{L}^{2}\left(55 \mathrm{mg}^{2} / \mathrm{dL}^{2}\right)$ to reduce the risk of ectopic calcifications and advise consideration of a low phosphate diet and, in certain cases, phosphate binders as needed to control phosphate levels [12-14].

In patients with hypoparathyroidism, daily subcutaneous (SC) treatment with recombinant human PTH (rhPTH (1-84), PTH rDNA; NATPARA ${ }^{\circledR}$; Shire-NPS Pharmaceuticals, Inc., Lexington, MA, USA) has the potential to reproduce some of the physiologic effects of PTH compared with conventional therapy, such as lowering serum phosphate levels, promoting conversion of $25(\mathrm{OH}) \mathrm{D}$ to active $1,25(\mathrm{OH})_{2} \mathrm{D}$, and improving renal tubular reabsorption of calcium. rhPTH(1-84) is identical to native human PTH $[15,16]$. Treatment of hypoparathyroidism with rhPTH (1-84) has been studied in several recently published clinical trials [16-21]. In short, these studies demonstrate that treatment with $\operatorname{rhPTH}(1-84)$ is associated with reduced requirements for oral calcium and active vitamin $\mathrm{D}$ while maintaining control of symptoms, and some studies provide evidence for improved quality of life. The pivotal registration study for rhPTH(1-84), REPLACE, was a 24-week, randomized, double-blind, placebo-controlled, phase III, multicenter study that demonstrated that once-daily SC injections of rhPTH(1-84) reduced both oral calcium and active vitamin $\mathrm{D}$ requirements by $\geq 50 \%$ from baseline levels while maintaining albumin-corrected total serum calcium levels in the target range $(1.9 \mathrm{mmol} / \mathrm{L}$ to laboratory upper limit of normal) at Week 24 [19]. $53 \%$ of patients who received rhPTH(1-84) achieved this endpoint compared with $2 \%$ who received placebo $(P<0.0001)$. Complete independence from calcitriol or alfacalcidol and reduction of daily calcium doses to $\leq 500 \mathrm{mg} /$ day while maintaining serum calcium in the target range was achieved by $43 \%$ of the rhPTH(1-84) group compared with $5 \%$ of the placebo group $(P<0.0001)$.

In this report, we present additional relevant results from the largest randomized, placebo-controlled trial completed in this endocrine-deficiency disease population. This information provides a greater understanding of the effects of rhPTH(1-84) beyond the previously reported composite primary endpoint of the REPLACE study [19]. Using predefined individual REPLACE clinical study exploratory endpoints, relevant serum and urine data collected during the trial were analyzed for the effects of $\operatorname{rhPTH}(1-84)$ on phosphate homeostasis and vitamin D metabolism.

\section{Materials and methods}

\section{Study design}

Detailed inclusion and exclusion criteria have been reported by Mannstadt et al. [19]. Briefly, patients between 18 and 85-years-old were defined as having hypoparathyroidism based on hypocalcemia and documented PTH levels below the lower limit of the normal range at least twice within the previous 12 months [19]. The study was conducted in 32 outpatient centers in accordance with Good Clinical Practice guidelines and the Declaration of Helsinki, and all study patients provided informed consent. This study is registered with ClinicalTrials.gov (NCT00732615) and EU clinical trials register (EudraCT 2008-005063-34).

During an optimization period over the first 2-16 weeks of the study, active vitamin D (calcitriol or alfacalcidol) and calcium doses were adjusted, as previously described [19]. During the optimization phase, native vitamin D doses were adjusted as follows: patients with serum $25(\mathrm{OH}) \mathrm{D}$ levels below the lower limit of normal $(<75 \mathrm{nmol} / \mathrm{L})$ were supplemented with vitamin $\mathrm{D}_{3}$ at $2000 \mathrm{IU} /$ day until levels reached the normal range $(75 \mathrm{nmol} / \mathrm{L}-250 \mathrm{nmol} / \mathrm{L})$, patients 
with serum $25(\mathrm{OH}) \mathrm{D}$ levels in the normal range received maintenance vitamin $\mathrm{D}_{3}$ at $400 \mathrm{IU} / \mathrm{day}$, and patients with serum $25(\mathrm{OH}) \mathrm{D}$ levels above the normal range did not receive vitamin $D_{3}$.

After calcium and active vitamin D doses were stable for a 2-week period, which established the baseline doses, patients were randomized in a 1:2 ratio to receive once-daily $\mathrm{SC}$ injections of placebo or $50 \mu \mathrm{g} \operatorname{rhPTH}(1-84)$. The 24week treatment period began with a stepwise titration phase that allowed for 2 uptitrations of $\operatorname{rhPTH}(1-84)$ dose, if needed, to reduce active vitamin D first and then oral calcium, as previously described [19]. The titration phase was followed by a maintenance phase for the remainder of the treatment period; rhPTH(1-84) could be downtitrated at any time, if necessary, but not uptitrated. Adjustments were permitted in active vitamin $\mathrm{D}$ and oral calcium doses to maintain serum calcium in the target range and to improve hypercalciuria at any time during the treatment period. During the treatment phase, patients received at least 400 IU/day of vitamin $\mathrm{D}_{3}$; patients with serum $25(\mathrm{OH}) \mathrm{D}$ levels below the lower limit of normal received additional vitamin $\mathrm{D}_{3}$ as necessary to bring levels into the normal range. rhPTH(1-84) was discontinued at the conclusion of 24 weeks, whereby baseline oral calcium and active vitamin D were resumed, and patients were followed up for 4 weeks.

\section{Assessments}

The assessments for serum phosphate levels were scheduled at baseline and Weeks 1, 2, 3, 4, 5, 6, 8, 12, 16, 20, and 24, and 24-hour urine phosphate measurements were done at baseline and Weeks 3, 5, 6, 8, 12, 16, and 24. Serum phosphate was measured $24 \mathrm{~h}$ after the last injection of rhPTH(1-84) or placebo, as part of a 24-analyte serum chemistry panel that required fasting for $\geq 8 \mathrm{~h}$ before testing. Reported serum phosphate values in $\mathrm{mg} / \mathrm{dL}$ were converted to International System of Units ( $\mathrm{mmol} / \mathrm{L})$ using a standard conversion factor of 0.323 [22]. Serum levels of $25(\mathrm{OH}) \mathrm{D}$ were assessed at baseline and $24 \mathrm{~h}$ after the last injection of rhPTH(1-84) or placebo at Weeks 2, 4, 6, 12, and 24 by chemiluminescent assay. Serum levels of $1,25(\mathrm{OH})_{2} \mathrm{D}$ were also assessed at baseline and $24 \mathrm{~h}$ after the last study drug injection at Weeks 12 and 24 by extraction chromatography followed by radioreceptor assay.

\section{Statistical analysis}

Treatment group differences for serum and urine phosphate were compared using an analysis of covariance model, with actual change as the dependent variable, treatment as a factor, and baseline value as a covariate. Treatment group differences for active vitamin D dose were compared using an analysis of covariance model, with percentage change as the dependent variable, treatment as a factor, and the baseline dose as a covariate. A converted active vitamin D value was used, in which 2 doses of alfacalcidol were equated to 1 dose of calcitriol [23]. The albumin-corrected serum calcium levels were measured and calculated as previously described [19]. The $P$ values for inter-treatment group comparison of differences were calculated from the least squares mean difference and standard error.

During the US regulatory review of the $\operatorname{rhPTH}(1-84)$ application for the treatment of patients with hypoparathyroidism, the sponsor was requested to re-evaluate the REPLACE data based on 124 study patients from 31 centers in North America and Europe, after data from one clinical site was removed. Mannstadt et al. had reported that the 134 patients with hypoparathyroidism randomized in the REPLACE study met the primary efficacy endpoint and had a generally safe profile [19]. After all comparisons and analyses were recalculated, there was no change in the primary endpoint efficacy and safety conclusions, and the US Prescribing Information cites the data analysis from 124 study patients [24]. This exploratory analysis report also evaluated the matching 124-patient data set, and for completeness in data analysis provides the re-analyzed primary calcium values in the supplementary material.

\section{Results}

Of the 124 patients analyzed, 84 were in the $\operatorname{rhPTH}(1-84)$ group and 40 were in the placebo group, reflecting the $2: 1$ randomization. Table 1 summarizes key patient demographics and baseline characteristics. $79 \%$ of patients were women. The mean \pm SD age was $47.3 \pm 12.7$ years, body mass index was $29.2 \pm 6.1 \mathrm{~kg} / \mathrm{m}^{2}$, and duration of hypoparathyroidism was $13.6 \pm 10.3$ years. Twelve patients discontinued treatment before study completion: 5 in the rhPTH(1-84) group and 7 in the placebo group. Of these, two patients, both in the $\operatorname{rhPTH}(1-84)$ group, withdrew because of an adverse event (one patient had several adverse events, some of which were judged to be treatment related; the other patient had a cerebrovascular accident that was not thought to be related to treatment).

\section{Phosphate levels}

At screening, mean \pm SD serum phosphate level for the study group was in the upper normal range at $1.5 \pm 0.3$ $\mathrm{mmol} / \mathrm{L}$ (normal range, $0.8-1.6 \mathrm{mmol} / \mathrm{L}$ [25]). After optimization, baseline serum phosphate levels were similar for both treatment groups $(1.5 \pm 0.2 \mathrm{mmol} / \mathrm{L}$ for each). The time course data in Fig. 1a demonstrate that the serum phosphate levels in patients receiving $\operatorname{rhPTH}(1-84)$, 
Table 1 Patient population characteristics at baseline (after optimization of active vitamin D and calcium doses)

\begin{tabular}{|c|c|c|c|}
\hline Variable & $\begin{array}{l}\text { rhPTH(1-84) } \\
(n=84)\end{array}$ & $\begin{array}{l}\text { Placebo } \\
(n=40)\end{array}$ & $\begin{array}{l}\text { Reference range } \\
\text { (If applicable) }\end{array}$ \\
\hline Mean (range) age, years & $46.6(19-74)$ & $48.9(21-73)$ & \\
\hline Women (men), $n$ & $65(19)$ & $33(7)$ & \\
\hline Mean \pm SD body mass index, $\mathrm{kg} / \mathrm{m}^{2}$ & $29.3 \pm 6.4$ & $28.9 \pm 5.3$ & \\
\hline Duration (range) of hypoparathyroidism, years & $14.6(2-50)$ & $11.6(2-38)$ & \\
\hline \multicolumn{4}{|l|}{ Baseline characteristics after optimization period } \\
\hline \multicolumn{4}{|l|}{ Prescribed calcium, $n(\%)$} \\
\hline 0-2000 mg/day & $57(68)$ & $29(72.5)$ & \\
\hline \multirow[t]{2}{*}{$>2000 \mathrm{mg} /$ day } & $27(32)$ & $11(27.5)$ & \\
\hline & Mean \pm SD & Mean \pm SD & \\
\hline Prescribed native vitamin $\mathrm{D},{ }^{\mathrm{a}} \mathrm{IU} /$ day & $2217 \pm 6875$ & $1467 \pm 3971$ & \\
\hline Prescribed calcitriol, ${ }^{\mathrm{b}} \mu \mathrm{g} / \mathrm{day}$ & $0.9 \pm 0.5$ & $0.8 \pm 0.4$ & \\
\hline Serum $25(\mathrm{OH}) \mathrm{D}$ levels, $\mathrm{nmol} / \mathrm{L}$ & $105.5 \pm 37.0$ & $110.9 \pm 47.4$ & $75-250$ \\
\hline Serum $1,25(\mathrm{OH})_{2} \mathrm{D}$ levels, $\mathrm{pmol} / \mathrm{L}$ & $87.6 \pm 55.1$ & $85.0 \pm 29.9$ & $39-156$ \\
\hline \multicolumn{4}{|l|}{ Calcium parameters } \\
\hline Serum calcium, ${ }^{\mathrm{c}} \mathrm{mmol} / \mathrm{L}$ & $2.1 \pm 0.2$ & $2.2 \pm 0.2$ & $2.1-2.6$ \\
\hline Urinary calcium, $\mathrm{mmol} / 24 \mathrm{~h}$ & $9.0 \pm 4.8$ & $8.4 \pm 4.3$ & $1.3-7.5$ \\
\hline \multicolumn{4}{|l|}{ Phosphate parameters } \\
\hline Serum phosphate, $\mathrm{mmol} / \mathrm{L}$ & $1.5 \pm 0.2$ & $1.5 \pm 0.2$ & $0.8-1.6$ \\
\hline Urinary phosphate, $\mathrm{mmol} / 24 \mathrm{~h}$ & $34.2 \pm 14.2$ & $33.7 \pm 12.0$ & $12.9-42.0$ \\
\hline Serum magnesium, $\mathrm{mmol} / \mathrm{L}$ & $0.83 \pm 0.08$ & $0.84 \pm 0.07$ & $0.65-1.05$ \\
\hline Calcium-phosphate product, $\mathrm{mmol}^{2} / \mathrm{L}^{2}$ & $3.22 \pm 0.54$ & $3.29 \pm 0.52$ & $<4.4$ \\
\hline
\end{tabular}

rhPTH recombinant human parathyroid hormone, $U L N$ upper limit of normal

${ }^{a}$ Among those patients receiving native vitamin $\mathrm{D}(\operatorname{rhPTH}(1-84), n=61$; placebo, $n=24)$

${ }^{\mathrm{b}}$ Alphacalcidol dose is converted to calcitriol dose based on a conversion factor of 2 alphacalcidol equals 1 calcitrio

${ }^{c}$ Albumin-corrected total serum calcium measured $24 \mathrm{~h}$ after the last injection, decreased rapidly from baseline. At Week 1 (the first on-treatment study visit), serum phosphate had declined by $0.2 \pm 0.02 \mathrm{mmol} / \mathrm{L}$ (least squares mean $\pm \mathrm{SE}$ ). In contrast, in the placebo group, serum phosphate was unchanged at Week 1 (change from baseline: $0.0 \pm 0.03 \mathrm{mmol} / \mathrm{L} ; P<0.001$ vs. $\operatorname{rhPTH}(1-84)$ ). This initial decrease in serum phosphate with $\operatorname{rhPTH}(1-84)$ was maintained between Weeks 1 and 24, and was significantly lower compared with the placebo arm in which levels remained near baseline. Furthermore, at every study visit between Weeks 1 and 24, serum phosphate levels remained stable and were significantly lower in the rhPTH (1-84) treatment arm compared with the placebo arm. At Week 24 , serum phosphate declined by $0.2 \pm 0.02 \mathrm{mmol} / \mathrm{L}$ in $\operatorname{rhPTH}(1-84)$-treated patients and did not change in placebo-treated patients (change from baseline: $0.0+0.03$ $\mathrm{mmol} / \mathrm{L} ; P<0.001)$.

Baseline 24-h urine phosphate excretion levels were similar in both treatment groups (rhPTH (1-84), 34.2 \pm $14.2 \mathrm{mmol} / 24 \mathrm{~h}$; placebo, $33.7 \pm 12.0 \mathrm{mmol} / 24 \mathrm{~h}$ ). In contrast to serum phosphate measurements, urinary phosphate data showed substantial variability, and no significant change between the groups was apparent until Week 12 (Fig. 1b). At Week 12, the significant decrease in urinary phosphate levels in the rhPTH(1-84) group was $5.4 \pm 1.9$ $\mathrm{mmol} / 24 \mathrm{~h}$ compared with an increase of $2.4 \pm 3.0 \mathrm{mmol} /$ $24 \mathrm{~h}$ in the placebo group (least squares mean $\pm \mathrm{SE} ; P=$ 0.03 ). At Week 24, 24-h urinary phosphate excretion levels had decreased in both treatment arms relative to baseline; the decrease was $6.1 \pm 1.4 \mathrm{mmol} / 24 \mathrm{~h}$ in patients receiving rhPTH(1-84) compared with a decrease of $2.4 \pm 2.1 \mathrm{mmol} /$ $24 \mathrm{~h}$ in patients receiving placebo $(P=0.15)$.

\section{Calcium-phosphate product levels}

Prescribed calcium dose, albumin-corrected serum calcium and urinary calcium at baseline and Week 24, and time course data for serum calcium are presented in Supplementary Tables 1 and 2; these data confirm the observed reductions reported in the primary endpoint study analysis [19]. At baseline after optimization, mean \pm SD calcium-phosphate product levels were similar for both 
Fig. 1 Change from baseline in serum phosphate a and urinary phosphate b during treatment with rhPTH(1-84) or placebo in patients with

hypoparathyroidism. Change from baseline values is least squares mean \pm SE. rhPTH $=$ recombinant human parathyroid hormone. $* P \leq 0.004$ a or $P=$ $0.03 \mathbf{b}$ for the mean change from baseline for the rhPTH(1-84) vs. placebo
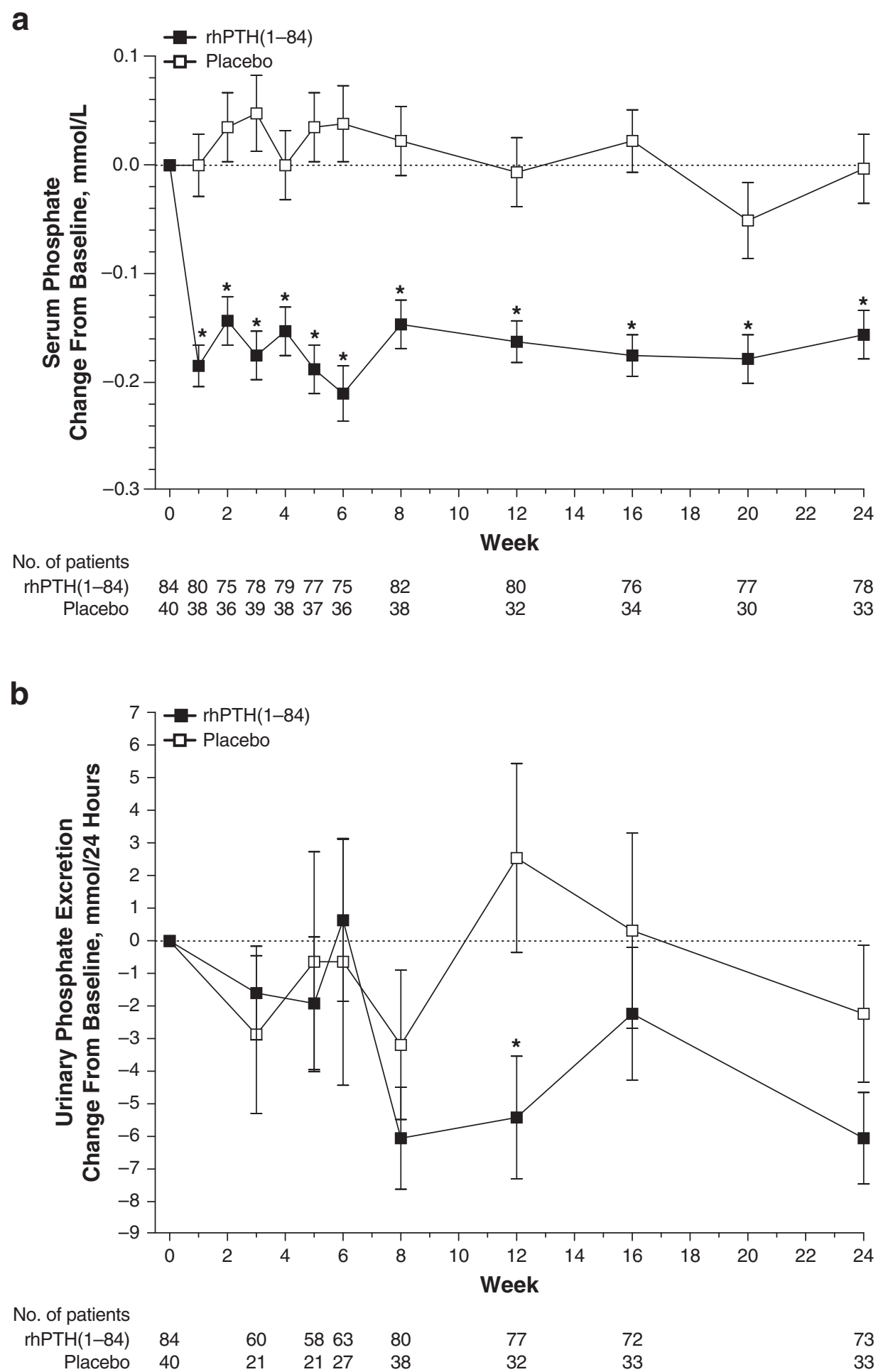

treatment groups $\left(\operatorname{rhPTH}(1-84), 3.2 \pm 0.5 \mathrm{mmol}^{2} / \mathrm{L}^{2}\right.$; placebo, $3.3 \pm 0.5 \mathrm{mmol}^{2} / \mathrm{L}^{2}$; Fig. 2). Calcium-phosphate product levels decreased rapidly in the rhPTH(1-84) treatment arm; at Week 1, calcium-phosphate product levels declined to $2.9 \pm 0.5 \mathrm{mmol}^{2} / \mathrm{L}^{2}$. In contrast, the levels in the placebo group remained steady; Week 1 levels were $3.2 \pm$ $0.4 \mathrm{mmol}^{2} / \mathrm{L}^{2}$. These values were generally maintained over the remainder of the study: at Week 24, calcium-phosphate product levels were $2.8 \pm 0.5 \mathrm{mmol}^{2} / \mathrm{L}^{2}$ in patients receiving $\operatorname{rhPTH}(1-84)$ and $3.2 \pm 0.4 \mathrm{mmol}^{2} / \mathrm{L}^{2}$ in patients 
Fig. 2 Time course of change in calcium-phosphate product during treatment with rhPTH (1-84) or placebo in patients with hypoparathyroidism measured before the next injection. Values are mean \pm SD. rhPTH $=$ recombinant human parathyroid hormone

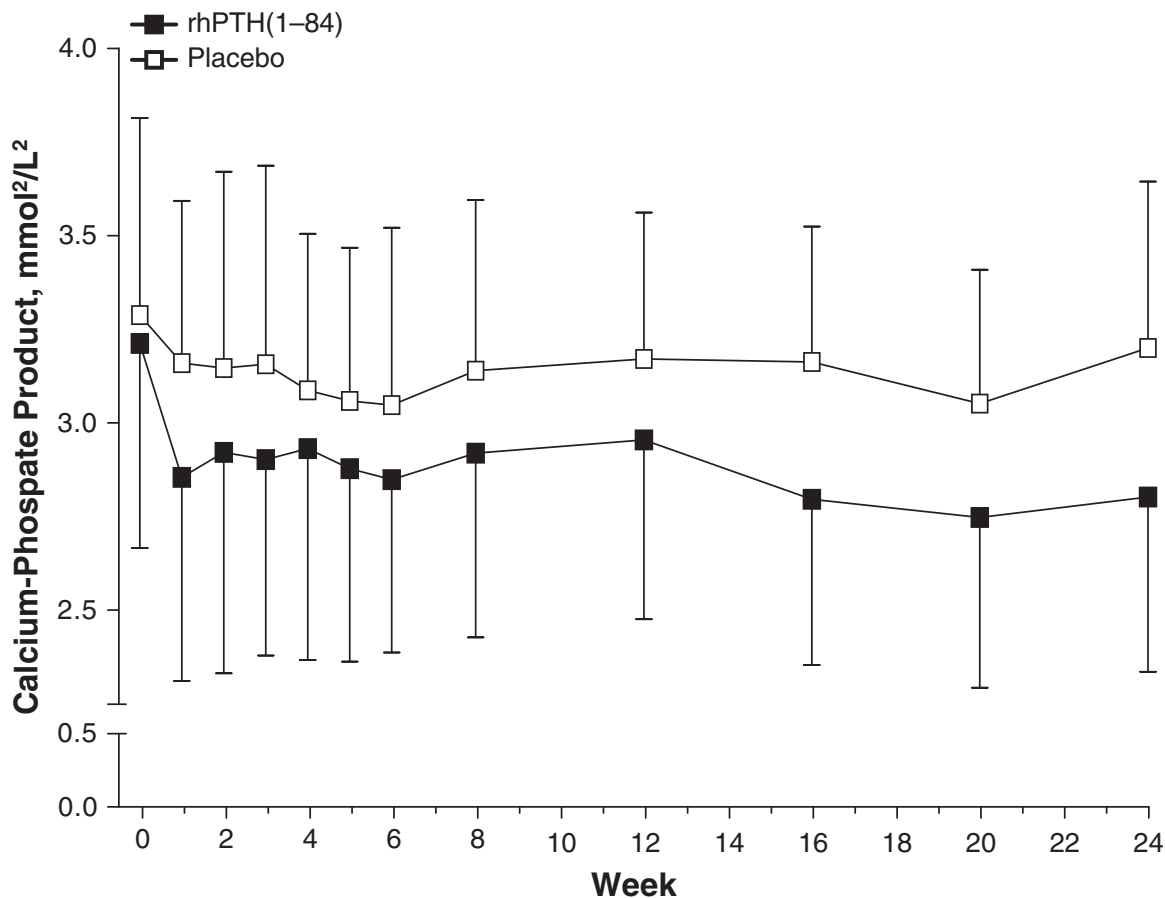

No. of patients rhPTH(1-84) Placebo receiving placebo. The least squares mean \pm SE change in the calcium-phosphate product from baseline to Week 24 between the treatment arms was significantly different: there was a decrease of $0.4 \pm 0.1 \mathrm{mmol}^{2} / \mathrm{L}^{2}$ in the $\operatorname{rhPTH}(1-84)$ group and a decrease of only $0.1 \pm 0.1 \mathrm{mmol}^{2} / \mathrm{L}^{2}$ in the placebo group $(P<0.001)$.

\section{Native vitamin D}

When the mean daily dose is calculated from the total dose over the treatment period, patients on $\operatorname{rhPTH}(1-84)$ were on a higher dose of oral native vitamin $\mathrm{D}$ compared with patients in the placebo group $(1487 \pm 2127$ IU/day vs. 917 $\pm 1312 \mathrm{IU} /$ day; mean $\pm \mathrm{SD}$ ). After optimization, baseline serum levels of $25(\mathrm{OH}) \mathrm{D}$ were within the normal range and were similar for both treatment groups (Table 1 and Fig. 3a). Among patients receiving $\mathrm{rhPTH}(1-84)$, serum 25 $(\mathrm{OH}) \mathrm{D}$ levels declined steadily between baseline and Week 12 , and then stabilized, whereas in patients receiving placebo, serum 25(OH)D levels decreased only slightly within the first 4 weeks and stayed near baseline levels. At Weeks 2 and 12 , mean $\pm \mathrm{SD}$ serum $25(\mathrm{OH}) \mathrm{D}$ levels declined by $14.1 \pm 18.6 \mathrm{nmol} / \mathrm{L}$ and $32.3 \pm 31.8 \mathrm{nmol} / \mathrm{L}$, respectively, in the $\operatorname{rhPTH}(1-84)$ group and remained below baseline until Week 24 (change from baseline: $-24.9 \pm 39.2 \mathrm{nmol} / \mathrm{L}$ ). In contrast, there was no change in the placebo group on serum $25(\mathrm{OH}) \mathrm{D}$ levels (mean \pm SD change from baseline at Week 24: $-3.1 \pm 33.6 \mathrm{nmol} / \mathrm{L})$.

\section{Activated vitamin D}

After optimization, baseline serum levels of $1,25(\mathrm{OH})_{2} \mathrm{D}$ were within the normal range and were similar for both treatment groups (Table 1 and Fig. $3 b$ ). The mean \pm SD baseline active vitamin $\mathrm{D}$ dose was $0.9 \pm 0.5 \mu \mathrm{g} /$ day in patients receiving $\mathrm{rhPTH}(1-84)$ and $0.8 \pm 0.4 \mu \mathrm{g} / \mathrm{day}$ in patients receiving placebo; 67 and $62 \%$ of patients treated with $\operatorname{rhPTH}(1-84)$ or placebo, respectively, were taking $>0.5 \mu \mathrm{g} /$ day calcitriol or $>1.0 \mu \mathrm{g} /$ day alfacalcidol. At the beginning of the treatment period, active vitamin $\mathrm{D}$ doses were reduced per study protocol; in the initial 2 weeks, the reductions were $51 \pm 4 \%$ and $51 \pm 6 \%$ (least squares mean $\pm \mathrm{SE}$ percentage change from baseline values), for $\mathrm{rhPTH}(1-84)$-treated and placebo-treated patients, respectively (Supplementary Fig. 1). Patients in the rhPTH(1-84) group continued dose reductions until Week $8(90 \pm 4 \%$ reduction) and ended treatment at Week 24 with a $77 \pm 4 \%$ reduction from baseline. In the placebo group, the dose decreased by $63 \pm 5 \%$ between baseline and Week 6 and ended treatment at Week 24 with a $35 \pm 7 \%$ reduction from baseline. By Week 24, dose reductions from baseline were significantly greater for patients receiving $\mathrm{rhPTH}(1-84)$ compared with patients receiving placebo $(P<0.001) ; 87 \%$ of patients receiving $\operatorname{rhPTH}(1-84)$ had a $\geq 50 \%$ reduction in active vitamin D dose compared with $45 \%$ of patients receiving placebo. There were fewer measurements of serum levels of 
Fig. 3 Time course of change in serum 25-hydroxyvitamin D a and 1,25-dihydroxyvitamin D b during treatment with $\mathrm{rhPTH}$ (1-84) or placebo in patients with hypoparathyroidism.

Values are mean \pm SD. rhPTH

$=$ recombinant human parathyroid hormone a

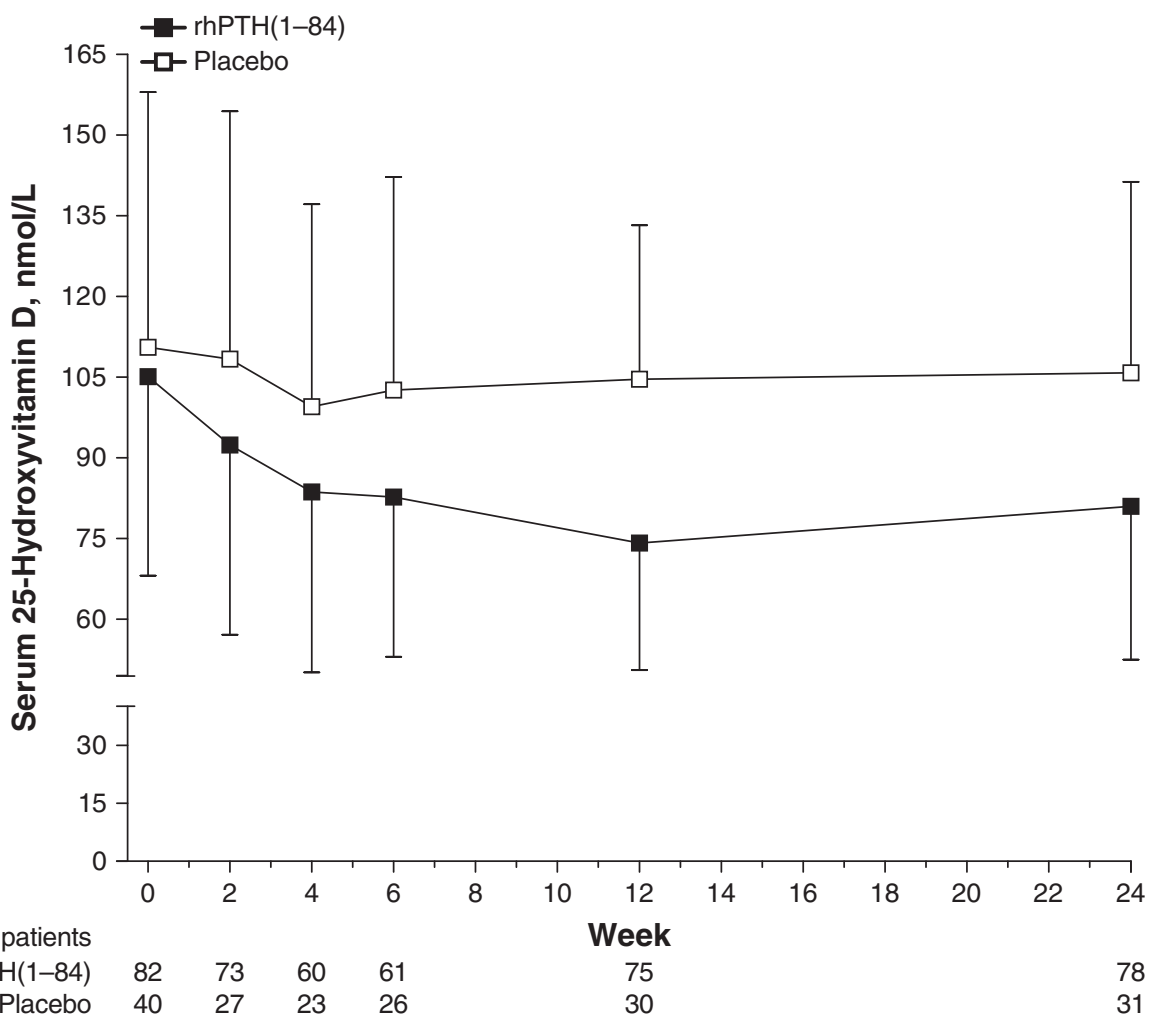

b

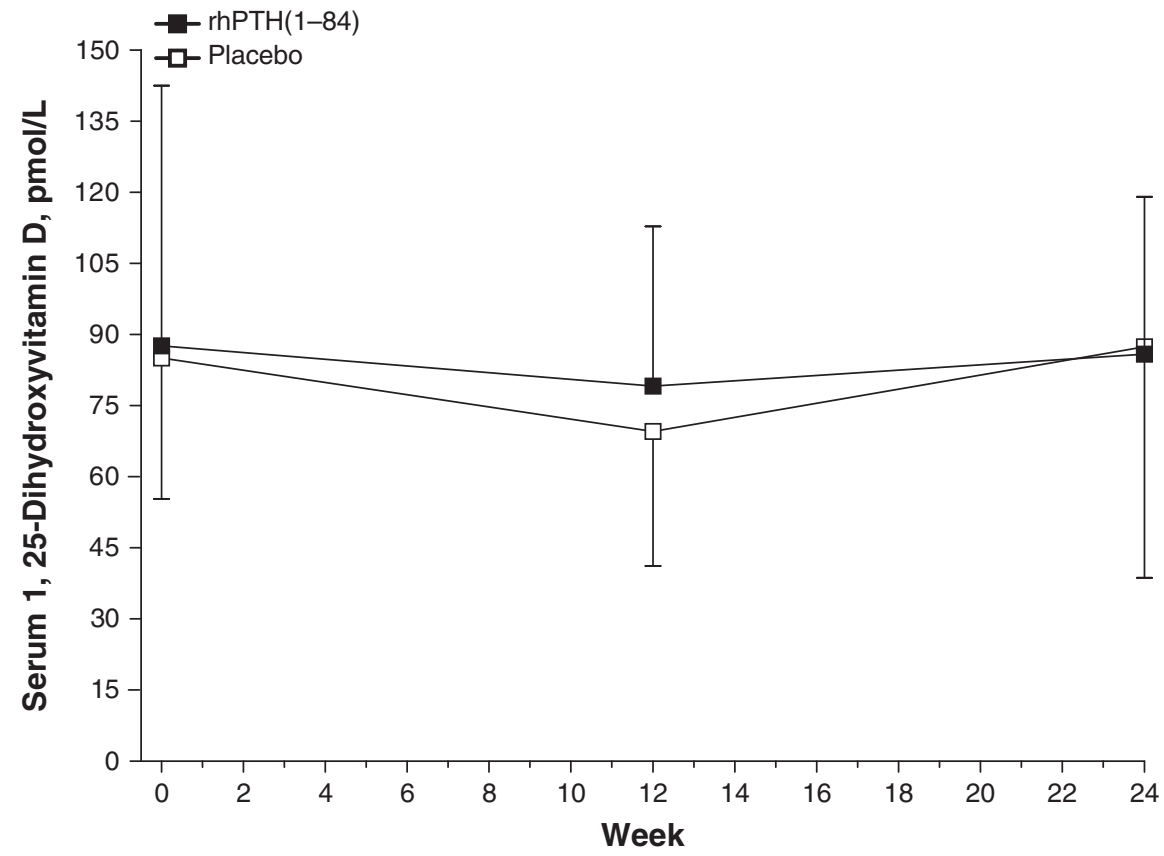

No. of patients

rhPTH(1-84) 82

Placebo $\quad 40$
$1,25(\mathrm{OH})_{2} \mathrm{D}$ compared with serum $25(\mathrm{OH}) \mathrm{D}$ levels. Serum levels of $1,25(\mathrm{OH})_{2} \mathrm{D}$ remained stable throughout the study without major changes in both groups (change from baseline at Week 24 with $\operatorname{rhPTH}(1-84)$ and placebo: increase of $2.6 \pm 52.3 \mathrm{pmol} / \mathrm{L}$ and decrease of $0.8 \pm 45.0$ $\mathrm{pmol} / \mathrm{L}$, respectively). 
Among patients who achieved independence from oral active vitamin D $(62 \%, \operatorname{rhPTH}(1-84) ; 24 \%$, placebo), serum $1,25(\mathrm{OH})_{2} \mathrm{D}$ was maintained with $\operatorname{rhPTH}(1-84)$ treatment but decreased with placebo (change from baseline at Week 24, increase of $3.2 \pm 52.4 \mathrm{pmol} / \mathrm{L}$, and decrease of $25.0 \pm 27.9 \mathrm{pmol} / \mathrm{L}$, respectively, for these analytes).

\section{Discussion}

This analysis of exploratory endpoints from the pivotal phase III REPLACE study provides further evidence that rhPTH(1-84) therapy for patients with hypoparathyroidism is efficacious and has different effects from conventional treatment on serum phosphate, calcium-phosphate product, and vitamin D metabolites [19]. Here, we provided detailed time course data on the rapid changes in phosphate, calcium-phosphate product, and vitamin D metabolite levels with rhPTH(1-84) treatment.

On conventional therapy, serum phosphate levels often exceed the normal range during the day in patients with hypoparathyroidism [21]. Indeed, mean serum phosphate levels were in the upper range of normal in both groups at baseline, reflecting the lack of the phosphaturic effect of PTH [5]. Elevated serum phosphate levels are associated with a greater risk of soft tissue calcifications, likely via increases in calcium-phosphate product levels $[5,7$, 10-12]. In addition, preclinical studies suggest that high levels of serum phosphate may directly promote vascular calcification via osteochondrogenic conversion of vascular smooth muscle cells [26]. Among patients with end-stage renal disease or cardiovascular disease, elevated serum phosphate levels correlate with increased mortality risk [9, 27]. Our results show that, compared with placebo, rhPTH (1-84) treatment significantly decreased serum phosphate levels. It is noteworthy that the reductions reported here in serum phosphate levels and calcium-phosphate product were noticeable despite the fact that the measurements were made $24 \mathrm{~h}$ after the last PTH injection, a time point that reflects a minimal reduction in serum phosphate and calcium-phosphate product [21]. In a phase I pharmacodynamic (PD) and pharmacokinetic (PK) study conducted in patients with hypoparathyroidism, Clarke et al. reported that reductions in serum phosphate and calcium-phosphate product occur rapidly following $\mathrm{rPTH}(1-84)$ injection [21] and were maximal at $12 \mathrm{~h}$ following injection with 50-100 $\mu \mathrm{g} \operatorname{rhPTH}(1-84)$.

The decline in serum phosphate levels in the rhPTH (1-84) group was not accompanied by a corresponding increase in urinary phosphate excretion. Transient changes in urinary phosphate excretion may have been missed in this study because of the timing of assessments, and we may have captured only the new steady state. In the phase I
PK/PD study, serum phosphate decreased to a nadir at $5 \mathrm{~h}$ after injection of rhPTH(1-84), which was associated with a corresponding increase in urinary fractional excretion of phosphate over the same time course [21]. Similarly, Sikjaer et al. showed that urinary phosphate excretion increased over the first $8 \mathrm{~h}$ post-injection of $\operatorname{rhPTH}(1-84)$, followed by a return to near-baseline levels over the next $16 \mathrm{~h}$ [28]. In the present study, the first post-baseline assessment of urinary phosphate was conducted after 1 week of rhPTH (1-84) treatment had been completed and $24 \mathrm{~h}$ after the last study drug dose. By 1 week of treatment with $\operatorname{rhPTH}(1-84)$, new steady-state serum phosphate levels may already be established, such that no further increases in urinary phosphate would be required to maintain the lower serum phosphate concentrations. Furthermore, while the study protocol did not restrict patients' dietary intake or the administration of phosphate binders, no patient took phosphate binders during the study. Thus, fluctuations in dietary phosphate during the study may also have contributed to the variability in urinary phosphate. Finally, compared with other time points, fewer patients had urine phosphate levels assessed at the early study visits (up to Week 6). The smaller sample sizes at these early time points may have contributed to the lack of consistent between-group differences at these time points. Nonetheless, the urinary phosphate data presented here might inform future studies investigating phosphate dynamics in hypoparathyroidism.

Although no prospective data exist in the hypoparathyroidism population, a somewhat arbitrary threshold of $4.4 \mathrm{mmol}^{2} / \mathrm{L}^{2}\left(55 \mathrm{mg}^{2} / \mathrm{dL}^{2}\right)$ is generally accepted as the upper limit of normal, and recent treatment guidelines include maintenance of calcium-phosphate product below that level as a goal of hypoparathyroidism management [13, 14]. Overall, our analysis showed that levels of calcium-phosphate product decreased to a greater extent in the rhPTH(1-84) group than in the placebo group. Furthermore, calcium-phosphate product levels declined rapidly with $\mathrm{rhPTH}(1-84)$ within 1 week of treatment. Decreases in calcium-phosphate product were evident with rhPTH(1-84) treatment despite the fact that serum calcium levels remained stable during the study. The observed reductions in calcium-phosphate product were likely driven primarily by rhPTH(1-84)-mediated decreases in serum phosphate. Together, these data suggest that, unlike conventional management strategies with oral calcium and active vitamin D therapy, treatment with $\operatorname{rhPTH}(1-84)$ improves phosphate levels and calcium-phosphate product in patients with hypoparathyroidism. Thus, $\operatorname{rhPTH}(1-84)$ has the potential to reduce complications, such as soft tissue calcification, compared with conventional therapy by more effectively restoring the full range of physiologic activities elicited by the endogenous hormone. 
The 2-16-week optimization period before randomization in the REPLACE study ensured that patients had optimized their conventional treatment with oral calcium and calcitriol or alfacalcidol and had normal serum $25(\mathrm{OH}) \mathrm{D}$ and magnesium levels. As a result, serum levels for both $25(\mathrm{OH}) \mathrm{D}$ and $1,25(\mathrm{OH})_{2} \mathrm{D}$ were within the normal range at baseline. Despite significant reductions in oral active vitamin $\mathrm{D}$ or even complete independence of active vitamin $\mathrm{D}$ in a subgroup, patients treated with $\operatorname{rhPTH}(1-84)$ maintained serum levels of the active vitamin $\mathrm{D}$ metabolite $1,25(\mathrm{OH})_{2} \mathrm{D}$ in the normal range. In contrast, placebotreated patients who eliminated oral active vitamin D experienced decreases in serum $1,25(\mathrm{OH})_{2} \mathrm{D}$. This reflects the physiologic role of PTH to enhance conversion of $25(\mathrm{OH}) \mathrm{D}$ to $1,25(\mathrm{OH})_{2} \mathrm{D}$. In addition, other metabolic pathways may be contributing to the turnover of $25(\mathrm{OH}) \mathrm{D}$ in patients treated with $\mathrm{rhPTH}(1-84)$, including catabolism by cytochrome $\mathrm{P} 450(\mathrm{CYP}) 24 \mathrm{~A} 1$ to generate $24,25(\mathrm{OH})_{2} \mathrm{D}$ [29]. In some cell types, CYP24A1 is known to be activated by PTH [29]. Because 25(OH)D constitutes the substrate for conversion to active vitamin $\mathrm{D}$, care has to be taken to keep $25(\mathrm{OH}) \mathrm{D}$ levels within the normal range in these patients. Consequently, over the course of the study, patients receiving $\mathrm{rhPTH}(1-84)$ had higher daily requirements for supplemental native vitamin $\mathrm{D}$ than patients receiving placebo, although the variability was large. Thus, administration of rhPTH(1-84) may permit reduction or elimination of oral calcium and active vitamin D supplementation, but native vitamin $\mathrm{D}$ supplementation should be continued. In practice, careful monitoring of serum $25(\mathrm{OH}) \mathrm{D}$ levels, as well as adjustments of oral native vitamin D supplementation as necessary, is warranted for patients receiving $\operatorname{rhPTH}(1-84)$.

The results reported here are consistent with other published data using different study designs and dosing regimens of $\operatorname{rhPTH}(1-84)[18,20]$. Cusano et al. reported that, among 27 patients treated with rhPTH(1-84) $100 \mu \mathrm{g}$ every other day, serum phosphate levels decreased from $1.4 \pm 0.6$ $\mathrm{mmol} / \mathrm{L}$ at baseline to approximately $1.3 \mathrm{mmol} / \mathrm{L}$ at 4 years and remained in the normal range throughout the study [18]. In a study of add-on $\operatorname{rhPTH}(1-84)$ therapy to standard treatment, Sikjaer et al. reported that serum phosphate levels decreased from $1.1 \mathrm{mmol} / \mathrm{L}$ at baseline to less than 1.0 $\mathrm{mmol} / \mathrm{L}$ in 32 patients receiving $\mathrm{rhPTH}(1-84) 100 \mu \mathrm{g}$ every day at 24 weeks [20]. Overall, median serum $25(\mathrm{OH}) \mathrm{D}$ was $72 \mathrm{nmol} / \mathrm{L}$ at baseline and did not change during the study. Serum $1,25(\mathrm{OH})_{2} \mathrm{D}$ was $98 \mathrm{pmol} / \mathrm{L}$ at baseline and increased rapidly in patients receiving $\mathrm{rhPTH}(1-84)$. Similar to our observations, levels in the Sikjaer study remained stable throughout that study, despite the marked dose reduction in active vitamin $\mathrm{D}$ (median reduction, 50 and $0 \%$ in patients treated with $\operatorname{rhPTH}(1-84)$ and placebo, respectively; $P<0.001)$.
As previously mentioned, a limitation in the REPLACE study was that serum phosphate and $1,25(\mathrm{OH})_{2} \mathrm{D}$ levels were measured $24 \mathrm{~h}$ after the last injection; therefore, we likely missed the maximal decrease of serum phosphate and calcium-phosphate product and the maximal increase in $1,25(\mathrm{OH})_{2} \mathrm{D}$ levels during the first $8 \mathrm{~h}$.

The REPLACE study demonstrated that daily SC treatment with $\operatorname{rhPTH}(1-84)$ allowed reductions in the large amounts of oral calcium and active vitamin D generally required for symptom management without increasing urinary calcium excretion [19]. This current analysis extends the primary findings of the REPLACE study and provides further mechanistic evidence that therapy with rhPTH(1-84), in contrast to conventional therapy with oral calcium and active vitamin $\mathrm{D}$, mimics the action of endogenous PTH in patients with hypoparathyroidism [12]. In summary, treatment with rhPTH(1-84) addresses the multiple physiologic mineral and vitamin D abnormalities that occur in hypoparathyroidism by decreasing serum phosphate levels toward the mid-normal range, improving the calcium-phosphate product, and maintaining serum $1,25(\mathrm{OH})_{2} \mathrm{D}$ levels in the normal range. This latter benefit will be maintained if careful monitoring of serum $25(\mathrm{OH}) \mathrm{D}$ levels and adjustments in oral native vitamin D supplementation as necessary are performed by the treating endocrinologist.

Acknowledgments Writing support was provided by Heather Heerssen, PhD, of Complete Healthcare Communications, LLC, (Chadds Ford, PA, USA) and was funded by NPS Pharmaceuticals, Inc. (Lexington, MA, USA).

Funding This study was funded by NPS Pharmaceuticals, Inc., a wholly owned indirect subsidiary of Shire.

\section{Compliance with ethical standards}

Conflict of interest BLC, JPB, and DMS have received institutional research grants from and served as advisory group members for NPS Pharmaceuticals, Inc.; MM and TJV have served as advisory group members for NPS Pharmaceuticals, Inc.; HL was an employee of NPS Pharmaceuticals, Inc., at the time the study was conducted and the manuscript was written.

Ethical approval All procedures performed in studies involving human participants were in accordance with the ethical standards of the institutional and/or national research committee and with the 1964 Declaration of Helsinki and its later amendments or comparable ethical standards.

Informed consent Informed consent was obtained from all individual participants included in the study.

Open Access This article is distributed under the terms of the Creative Commons Attribution 4.0 International License (http:// creativecommons.org/licenses/by/4.0/), which permits unrestricted use, distribution, and reproduction in any medium, provided you give appropriate credit to the original author(s) and the source, provide a 
link to the Creative Commons license, and indicate if changes were made.

\section{References}

1. T. Bohrer, I. Pasteur, O. Lyutkevych, P. Fleischmann, H. Sitter, N. Donner-Banzhoff, S. Rybakov, C. Hofmann, M. Tronko, M. Rothmund, Permanent postoperative hypoparathyroidism. An epidemiological clinical study using a new questionnaire instrument. J. Ukrainian Acad. Sci. 9, 476-494 (2003)

2. National Organization for Rare Disorders, Hypoparathyroidism. (2014) http://www.rarediseases.org/rare-disease-information/rarediseases/byID/703/viewAbstract. Accessed 15 September 2016

3. J.T. Potts Jr., Disorders of the parathyroid gland and calcium homeostasis. In: D.L. Longo, D.L. Kasper, J.L. Jameson, A.S. Fauci, S.L. Hauser, J. Loscalzo (eds.) Harrison's Principles of Internal Medicine, 18th Edition. McGraw-Hill, New York, pp. 3096-3120 (2012)

4. J.P. Bilezikian, A. Khan, J.T. Potts Jr., M.L. Brandi, B.L. Clarke, D. Shoback, H. Juppner, P. D’Amour, J. Fox, L. Rejnmark, L. Mosekilde, M.R. Rubin, D. Dempster, R. Gafni, M.T. Collins, J. Sliney, J. Sanders, Hypoparathyroidism in the adult: epidemiology, diagnosis, pathophysiology, target-organ involvement, treatment, and challenges for future research. J. Bone Miner. Res. 26(10), 2317-2337 (2011)

5. D. Shoback, Hypoparathyroidism. N. Engl. J. Med. 359(4), 391-403 (2008)

6. M.I. Khan, S.G. Waguespack, M.I. Hu, Medical management of postsurgical hypoparathyroidism. Endocr. Pract. 17(suppl 1), 18-25 (2011)

7. D.M. Mitchell, S. Regan, M.R. Cooley, K.B. Lauter, M.C. Vrla, C.B. Becker, S.A. Burnett-Bowie, M. Mannstadt, Long-term follow-up of patients with hypoparathyroidism. J. Clin. Endocrinol. Metab. 97(12), 4507-4514 (2012)

8. W.G. Goodman, J. Goldin, B.D. Kuizon, C. Yoon, B. Gales, D. Sider, Y. Wang, J. Chung, A. Emerick, L. Greaser, R.M. Elashoff, I.B. Salusky, Coronary-artery calcification in young adults with end-stage renal disease who are undergoing dialysis. N. Engl. J. Med. 342(20), 1478-1483 (2000)

9. G.A. Block, T.E. Hulbert-Shearon, N.W. Levin, F.K. Port, Association of serum phosphorus and calcium x phosphate product with mortality risk in chronic hemodialysis patients: a national study. Am. J. Kidney Dis. 31(4), 607-617 (1998)

10. S.K. Bhadada, A. Bhansali, V. Upreti, S. Subbiah, N. Khandelwal, Spectrum of neurological manifestations of idiopathic hypoparathyroidism and pseudohypoparathyroidism. Neurol. India 59(4), 586-589 (2011)

11. R. Goswami, R. Sharma, V. Sreenivas, N. Gupta, A. Ganapathy, S. Das, Prevalence and progression of basal ganglia calcification and its pathogenic mechanism in patients with idiopathic hypoparathyroidism. Clin. Endocrinol. (Oxf.) 77(2), 200-206 (2012)

12. M.L. Brandi, J.P. Bilezikian, D. Shoback, R. Bouillon, B. Clarke, R.V. Thakker, A. Khan, J.T. Potts Jr., Management of hypoparathyroidism: Summary statement and guidelines. J. Clin. Endocrinol. Metab. 101(6):2273-2283 (2016)

13. J.P. Bilezikian, M.L. Brandi, N.E. Cusano, M. Mannstadt, L. Rejnmark, R. Rizzoli, M.R. Rubin, K.K. Winer, U.A. Liberman, J. T. Potts Jr., Management of hypoparathyroidism: present and future. J. Clin. Endocrinol. Metab. 101(6):2313-2324 (2016)

14. J. Bollerslev, L. Rejnmark, C. Marcocci, D.M. Shoback, A. Sitges-Serra, W. van Biesen, O.M. Dekkers, European Society of
Endocrinology clinical guideline: treatment of chronic hypoparathyroidism in adults. Eur. J. Endocrinol. 173, G1-G120 (2015)

15. A.B. Hodsman, D.A. Hanley, M.P. Ettinger, M.A. Bolognese, J. Fox, A.J. Metcalfe, R. Lindsay, Efficacy and safety of human parathyroid hormone-(1-84) in increasing bone mineral density in postmenopausal osteoporosis. J. Clin. Endocrinol. Metab. 88(11), 5212-5220 (2003)

16. M.R. Rubin, J. Sliney Jr., D.J. McMahon, S.J. Silverberg, J.P. Bilezikian, Therapy of hypoparathyroidism with intact parathyroid hormone. Osteoporos. Int. 21(11), 1927-1934 (2010)

17. N.E. Cusano, M.R. Rubin, D.J. McMahon, D. Irani, L. Anderson, E. Levy, J.P. Bilezikian, PTH(1-84) is associated with improved quality of life in hypoparathyroidism through 5 years of therapy. J. Clin. Endocrinol. Metab. 99(10), 3694-3699 (2014)

18. N.E. Cusano, M.R. Rubin, D.J. McMahon, C. Zhang, R. Ives, A. Tulley, J. Sliney Jr., S.C. Cremers, J.P. Bilezikian, Therapy of hypoparathyroidism with $\mathrm{PTH}(1-84)$ : a prospective four-year investigation of efficacy and safety. J. Clin. Endocrinol. Metab. 98 (1), 137-144 (2013)

19. M. Mannstadt, B.L. Clarke, T. Vokes, M.L. Brandi, L. Ranganath, W.D. Fraser, P. Lakatos, L. Bajnok, R. Garceau, L. Mosekilde, H. Lagast, D. Shoback, J.P. Bilezikian, Efficacy and safety of recombinant human parathyroid hormone (1-84) in hypoparathyroidism (REPLACE): a double-blind, placebo-controlled, randomized, phase 3 study. Lancet Diabetes Endocrinol. 1(4), 275-283 (2013)

20. T. Sikjaer, L. Rejnmark, L. Rolighed, L. Heickendorff, L. Mosekilde; Hypoparathyroid Study Group, The effect of adding PTH(1-84) to conventional treatment of hypoparathyroidism: a randomized, placebo-controlled study. J. Bone Miner. Res. 26 (10), 2358-2370 (2011)

21. B.L. Clarke, J.K. Berg, J. Fox, J.A. Cyran, H. Lagast, Pharmacokinetics and pharmacodynamics of subcutaneous recombinant parathyroid hormone (1-84) in patients with hypoparathyroidism: an open-label, single-dose, phase I study. Clin. Ther. 36(5), 722-736 (2014)

22. Kidney Disease: Improving Global Outcomes, CKD-MBD Work Group, KDIGO clinical practice guideline for the diagnosis, evaluation, prevention, and treatment of chronic kidney diseasemineral and bone disorder (CKD-MBD). Kidney Int. Suppl. 76 (113), S1-130 (2009)

23. T.C. Stamp, Calcitriol dosage in osteomalacia, hypoparathyroidism and attempted treatment of myositis ossificans progressiva. Curr. Med. Res. Opin. 7(5), 316-336 (1981)

24. Natpara ${ }^{\circledR}$ (parathyroid hormone) Full Prescribing Information. Shire-NPS Pharmaceuticals, Inc., Lexington, MA, (2016).

25. A. Testa, V. Fant, A. De Rosa, G.F. Fiore, V. Grieco, P. Castaldi, R. Persiani, S. Rausei, D. D'Ugo, G. De Rosa, Calcitriol plus hydrochlorothiazide prevents transient post-thyroidectomy hypocalcemia. Horm. Metab. Res. 38(12), 821-826 (2006)

26. C.M. Giachelli, The emerging role of phosphate in vascular calcification. Kidney Int. 75(9), 890-897 (2009)

27. M. Tonelli, G. Curhan, M. Pfeffer, F. Sacks, R. Thadhani, M.L. Melamed, N. Wiebe, P. Muntner, Relation between alkaline phosphatase, serum phosphate, and all-cause or cardiovascular mortality. Circulation 120(18), 1784-1792 (2009)

28. T. Sikjaer, A.K. Amstrup, R. Rolighed, S.G. Kjaer, L. Rejnmark, L. Mosekilde, PTH(1-84) replacement therapy in hypoparathyroidism: a randomized controlled trial on pharmacokinetic and dynamic effects following 6 months of treatment. J. Bone Miner. Res. 28(10), 2232-2243 (2013)

29. D.D. Bikle, Vitamin D metabolism, mechanism of action, and clinical applications. Chem. Biol. 21(3), 319-329 (2014) 